\title{
Chemoprevention of Helicobacter pylori-associated Gastric Carcinogenesis in a Mouse Model; Is It Possible?
}

\author{
Ki Baik Hahm*, Young Joon Song, Tae Young Oh, Jeong Sang Lee, Young-Joon Surh, \\ Young Bae Kim, Byung Moo Yoo, Jin Hong Kim, Sang Uk Han, Ki Taik Nahm, \\ Myung-Wook Kim, Dae Yong Kim and Sung Won Cho \\ Genomic Research Center for Gastroenterology, Ajou Helicobacter Research Group, \\ Ajou University School of Medicine, Suwon, Korea
}

Received 28 October 2002

\begin{abstract}
Although debates still exist whether Helicobacter pylori infection is really class I carcinogen or not, $H$. pylori has been known to provoke precancerous lesions like gastric adenoma and chronic atrophic gastritis with intestinal metaplasia as well as gastric cancer. Chronic persistent, uncontrolled gastric inflammations are possible basis for ensuing gastric carcinogenesis and $\boldsymbol{H}$. pylori infection increased COX-2 expressions, which might be the one of the mechanisms leading to gastric cancer. To know the implication of long-term treatment of antiinflammatory drugs, rebamipide or nimesulide, on $\mathrm{H}$. pylori-associated gastric carcinogenesis, we infected C57BL/6 mice with $H$. pylori, especially after MNU administration to promote carcinogenesis and the effects of the long-term administration of rebamipide or nimesulide were evaluated. C57BL/6 mice were sacrificed 50 weeks after $H$. pylori infection. Colonization rates of $\boldsymbol{H}$. pylori, degree of gastric inflammation and other pathological changes including atrophic gastritis and metaplasia, serum levels and mRNA transcripts of various mouse cytokines and chemokines, and NF-KB binding activities, and finally the presence of gastric adenocarcinoma were compared between $H$. pylori infected group (HP), and $H$. pylori infected group administered with long-term rebamipide containing pellet diets (HPR) or nimesulide mixed pellets (HPN). Gastric mucosal expressions of ICAM-1, HCAM, MMP, and transcriptional regulations of NF-KB binding were all significantly decreased in HPR group than in HP group. Multi-probe RNase protection assay showed the significantly decreased mRNA levels of apoptosis related genes and various cytokines genes like IFN- $\gamma$, RANTES, TNF- $\alpha$, TNFR p75, IL-1 $\beta$ in HPR group. In the
\end{abstract}

*To whom correspondence should be addressed.

Tel: 82-31-219-4383; Fax: 82-31-219-4399

E-mail: hahmkb@hotmail.com experiment designed to provoke gastric cancer through MNU treatment with $\boldsymbol{H}$. pylori infection, the incidence of gastric carcinoma was not changed between HP and HPR group, but significantly decreased in HPN group, suggesting the chemoprevention of $\boldsymbol{H}$. pylori-associated gastric carcinogenesis by COX-2 inhibition. Long-term administration of antiinflammatory drugs should be considered in the treatment of $\boldsymbol{H}$. pylori since they showed the molecular and biologic advantages with possible chemopreventive effect against $\boldsymbol{H}$. pylori-associated gastric carcinogenesis. If the final concrete proof showing the causal relationship between $\boldsymbol{H}$. pylori infection and gastric carcinogenesis could be obtained, that will shed new light on chemoprevention of gastric cancer, that is, that gastric cancer could be prevented through either the eradication of $\boldsymbol{H}$. pylori or lessening the inflammation provoked by $\boldsymbol{H}$. pylori infection in high risk group.

Keywords: Antiinflammation, Apoptosis, Chemoprevention, C57BL/6 mouse, Cytokines, Helicobacter pylori, Nimesulide, Rebamipide

The Causal Relationship and Mechanism between H. pylori Infection and Gastric Pathologies

The gastric inflammatory response induced by $H$. pylori consists of neutrophils, lymphocytes, plasma cells, and macrophages, along with varying degrees of epithelial cell degeneration and injury (Israel and Peek, 2001). As mechanisms by which $H$. pylori provoke gastric inflammations, the following two possibilities had been largely proposed. That is, one is that $H$. pylori secrete substances that stimulate mucosal inflammation from afar (Mai et al., 1992) and another mechanism is through direct 


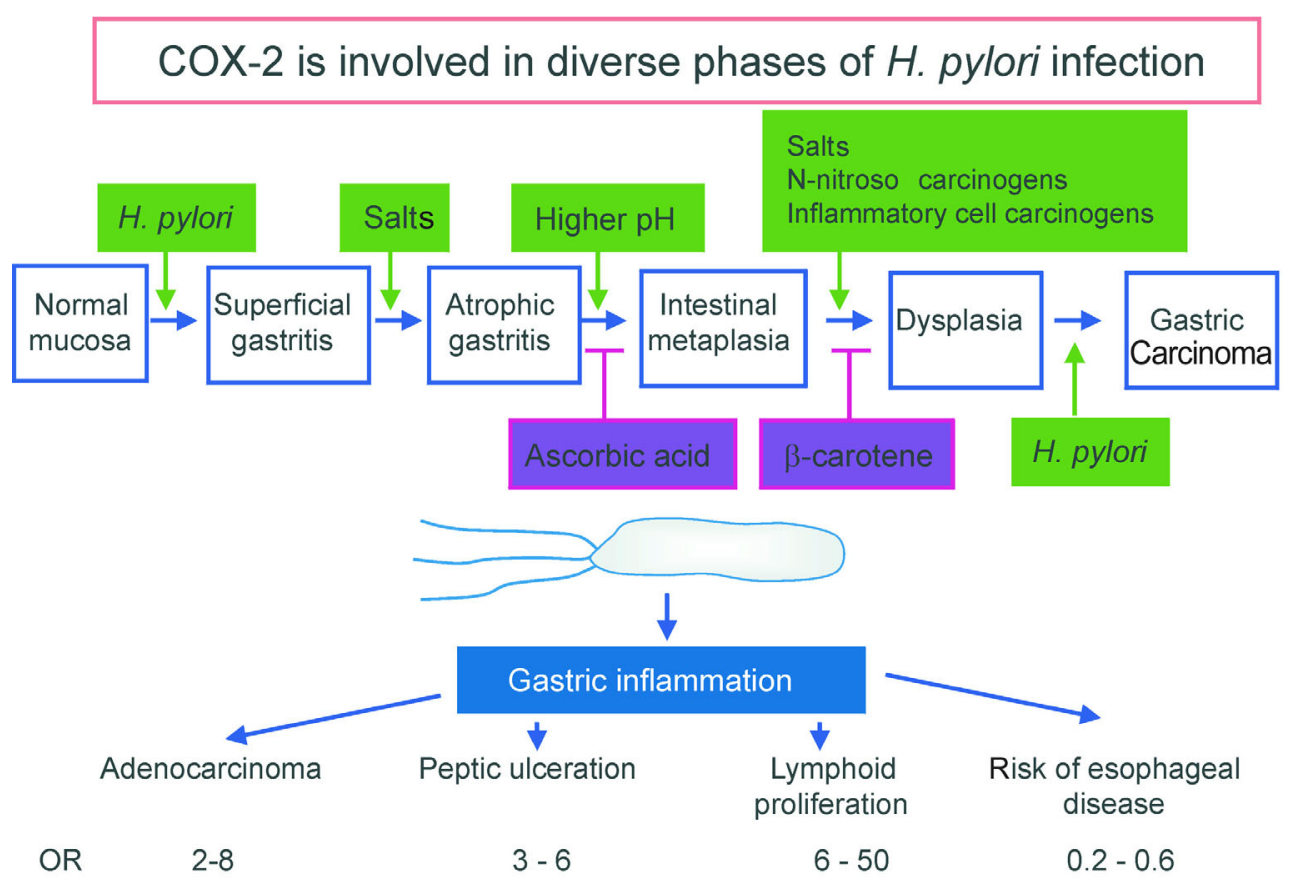

Fig. 1. Involvement of COX-2 in the various stages of $H$. pylori infection, providing insights about chemoprevention through the reduction of COX-2. H. pylori infection provoked superficial gastritis, atrophic gastritis, gastric dysplasia, and even gastric carcinoma, which led to the WHO's definition H. pylori as a class I carcinogen (1994 IARC, Lyon, France). The odd ratio of risk of gastric cancer by the $H$. pylori infection is 2-8. Interestingly, the $H$. pylori infection induced COX-2 expressions. Since COX-2 is largely regarded as responsible for tumorigenesis, the modulation of COX-2 levels or other inflammatory mediators might be intervening in the chemoprevention of the $H$. pylori-associated gastric carcinogenesis.

contact with gastric epithelial cells (through type IV secretory system) and stimulation of various cytokine releases (Yamaoka et al., 1996; Go, 1997), based on the fact that gastric epithelia from $H$. pylori-infected persons demonstrate enhanced levels of interleukin-1 $\beta$ (IL-1 $\beta$ ), IL-2, IL-6, IL-8, interferon- $\gamma$ (IFN- $\gamma$ ), and tumor necrosis factor- $\alpha$ (TNF- $\alpha)$ (Yoshida, 1993; Moss et al., 1994).

Another consequence of persistent inflammation may be alterations in cellular turnover. Gastric epithelial cell proliferation rates within colonized mucosa are significantly increased compared to those in uninfected controls (Bechi et al., 1996). In chronic $H$. pylori infection, there is a notable lack of epithelial cell necrosis, suggesting that other forms of cellular demise such as apoptosis may be induced (Peek et al., 1997). Although substantial variation exists among apoptosis scores in $H$. pylori infection, several studies have reported increased levels of gastric epithelial cell apoptosis among $H$. pylori-infected persons (Moss et al., 1996). H. pylori-induced gastritis may also lead to other forms of epithelial cell injury and damage. Activated neutrophils generate reactive oxygen or nitrogen species that can induce oxidative DNA damage via formation of DNA adducts (Rautelin et al., 1994; Zhang, 1996). Upon contact with $H$. pylori in vitro, an oxidative burst occurs within polymorphonuclear cells. The specific types of cellular damage resulting from generation of reactive oxygen species include lipid peroxidation, protein oxidation, and oxidation of DNA (Baik et al., 1996). All these mechanisms were principally involved in mucosal cell damages by $H$. pylori and some of these actions might be involved in $H$. pylori-associated gastric carcinogenesis. Therefore, some modifying trials will be needed to reduce the harmful injuries by $H$. pylori infection. The eradication of $H$. pylori infection itself or administration of blockers like NSAIDs or other antiinflammatory drugs will be the next candidate.

Nimesulide is one of the preferred inhibitor of cyclooxygenase-2 (COX-2) prescribed for anti-inflammation and pain relief (Davis et al., 1994). Several studies suggested these NSAIDs shed the possiblity of chemoprevention in colon carcinogenesis and preventing the development of colon adenoma or polyps (Reddy, 1996; Jacoby et al., 2000). Since COX-2 is highly expressed and induced in $H$. pylori infection and the attenuation of its expression was noted after the eradication of $H$. pylori (Sung et al., 2000), COX-2 inhibitor will be also one of the candidate for potential chemopreventive agent in $H$. pylori-associated gastric carcinogenesis (Fig. 1). Rebamipide has been reported to improve $H$. pylori-associated gastritis through either removing active oxygen species, scavenger of active oxygen species, or attenuating the productions of cytokines/chemokines (Yoshida, 1996; Arakawa et al., 1998). Until now although there have been several reports to document the effects and mechanisms of rebamipide in $H$. pylori-associated gastritis 


\author{
1 Normal control \\ 2. HP alone \\ 3. HP + Rebamipide \\ 4. $\mathrm{MNU} \rightarrow \mathrm{HP}$ \\ 5. MNU alone \\ 6. $\mathrm{MNU} \rightarrow \mathrm{HP}+$ Rebamipide \\ 7. $\mathrm{MNU} \rightarrow \mathrm{HP}+\mathrm{NSD}$
}

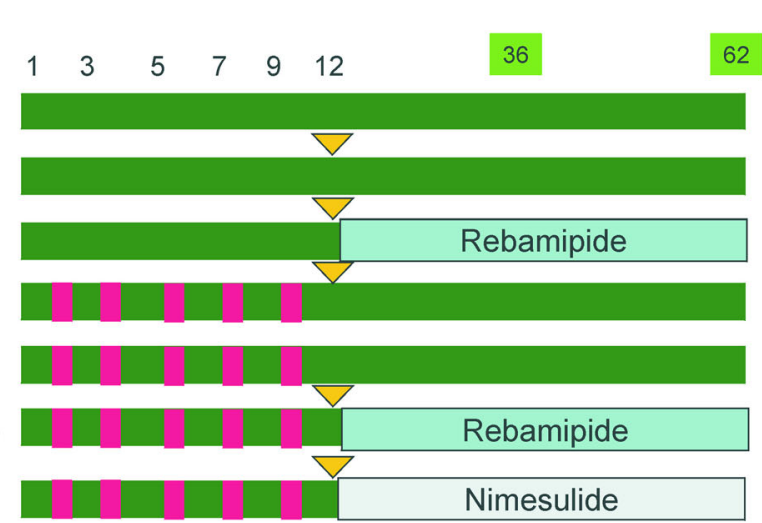

\footnotetext{
n-nitroso-N-methylurea (MNU) in drinking water at concentrations of $200 \mathrm{ppm}$

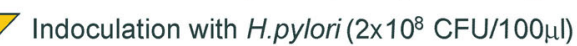

$\mathrm{R}$ Rebamipide $(10 \mathrm{mg} / \mathrm{kg})$ containing pellet diets

N Nimesulide containing pellet diets $(200$ ppm)
}

Fig. 2. Protocol for the study. Out of a total of 220 C57BL/6 mice, 180 mice were divided into 6 groups of 30 mice in each group (Groups 3 and 6 allocated 40 mice per group, due to the relatively low colonization rate of $H$. pylori than the other groups). They were given MNU that was mixed in their drinking water at concentrations of $200 \mathrm{ppm}$ (Groups 4-7) for a total of five cycles of one-week regimens with a one-week pause. After completion of the MNU administration, they were given autoclaved distilled water for two weeks. Groups 4, 6, and 7 were further inoculated with $H$. pylori three times every other day. H. pylori was given to mice without prior MNU treatment (Groups 2 and 3). The remaining 20 mice were given only distilled water, without $H$. pylori or MNU as noncarcinogen controls (Group 1).

and peptic ulcer disease (Yamasaki et al., 1987; Han, 1995), all these were done on designated periods of administration. Therefore, none was reported about the ex vivo effects of longterm administration of rebamipide or COX-2 inhibitors on $H$. pylori-associated gastritis. Recently we did do animal experiment to document the chemopreventive activities of anti-inflammatory drugs on $H$. pylori-associated gastric carcinogenesis, which will appear in the following section.

\section{Experiments Performed to Document Whether the Long-term Administration of Anti-inflammatory Drugs Can Modify the Process of MNU and H. pylori-associated Gastric Carcinogenesis}

Based on the assumption that chronic, persistent inflammation might predispose to carcinogenesis (Ernst, 1999), oxidative DNA damages and COX-2 expressions provoked by $H$. pylori infection could be reduced through the eradication of $H$. pylori, especially more effectively by the drug regimen including decreasing oxidative stress (Hahm et al., 1997), and gastric adenocarcinoma could be generated after long-term $H$. pylori infection in Mongolian gerbils or after coadministration of $H$. pylori and N-methyl-N-nitrosourea (MNU) (Sugiyama et al., 1998), we compared the pathological changes, changes of cellular proteins known to be involved in either inflammation or carcinogenesis and mRNA transcripts of cytokine and chemokine, and apoptosis related genes among normal controls, H. pylori-infected group, and long-term administration of anti-inflammatory drugs, nimesulide or rebamipide, after $H$. pylori infection. Since we could not observe the development of gastric cancer in mice model with $H$. pylori infection alone (Han et al., 2002), we added another set of experiment including MNU pretreatment with or without additional $H$. pylori infection for the current experiment. A total of two hundred twenty specific pathogen free, six-week-old female C57BL/6 mice were housed in steel cages on hard wood chip bedding in an airconditioned biohazard room with a $12 \mathrm{hr}$ light- $12 \mathrm{hr}$ dark cycle. N-methyl-N-nitrosourea (MNU) was prepared freshly twice a week by disolving in distilled water at concentrations of 200 p.p.m. The solutions were administered as drinking water in light-shielded bottles ad libitum. The mouse-adapted H. pylori (SS1, Sydney strain, kind gift of professor Adrian Lee), originally isolated from a peptic ulcer patient, were inoculated on Brucella agar plates containing $10 \%$ heatinactivated fetal bovine serum and Skirrow medium. They were kept at $37^{\circ} \mathrm{C}$ under micro-aerobic conditions using GasPak jar and CampyPak. After $24 \mathrm{hr}$ of fasting, $0.1 \mathrm{ml}$ suspension of $H$. pylori containing $1 \times 10^{8}$ colony-forming units $(\mathrm{CFU}) / \mathrm{ml}$ were delivered to mice intragastrically using an oral catheter. Rebamipide was administered mixed in chow pellet diets. According to preliminary data of Otsuka Pharmaceutical Research Center, treatment of rebamipide $20 \mathrm{mg} / \mathrm{kg} /$ day maintained $0.02 \%$ blood concentration of rebamipide. Nimesulides, a preferred COX-2 inhibitor (Davis 
et al., 1994), were also given CRF-1 diet containing 0.02\% nimesulide. The drug was mostly biotransformed into 4hydroxynimesulide, a metabolite with appears to contribute to the anti-inflammatory activity of the compound. The mean plasma concentrations of nimesulide became peak after 2-4 hours after administration. Since there was tendency mice refuse to take these pellet diets containing test drugs, the amounts consumed were monitored daily. Out of total two hundreds twenty C57BL/6 mice, 180 mice were divided into 6 groups of 30 mice in each group (Group 2 and Group 5 allocated 40 mice per group due to low colonization rate of $H$. pylori) and were given MNU mixed in their drinking water at concentrations of 200 p.p.m. (Group 4-7) for total five cycles of one-week regimen with one-week pause. After completion of MNU administration, they were given autoclaved distilled water for two weeks, and group 4, 6, and 7 were further inoculated with $H$. pylori three times every other day. $H$. pylori was given to 20 mice without prior MNU treatment (Group 2 and 3), and remaining 20 mice were given only distilled water without neither $H$. pylori nor MNU as noncarcinogen controls (Group 1). At the time points of 16 to 24 weeks after $H$. pylori administration, 10 mice from each group were sacrificed only to look at the presence of $H$. pylori by direct cultures and CLO test. The observation period was extended up to 50 weeks after $H$. pylori infection. These experimental protocols were summarized in Fig. 2.

All animals were sacrificed under deep ether anesthesia at $50^{\text {th }}$ week after the $H$. pylori infection. The stomachs, opened along the greater curvature, were fixed in $10 \%$ neutralized formalin in phosphate buffered saline, processed by standard methods, and embedded in paraffin. Tissues were sectioned at
$4 \mu \mathrm{m}$ for hematoxylin and eosin staining. Histological typing of adenocarcinoma was based on the predominant pattern of tumor and the lesions of the glandular stomach were classified by the following criteria. Tubular adenocarcinomas were defined as tumor cells with cellular atypia, nuclear anisonucleosis, hyperchromatism, thickened and irregular nuclear membrane, and stromal invasion or architectural destruction. Signet ring cell carcinomas were defined as isolated tumor cells containing large amounts of mucins. Adenoma was defined as proliferative immature glandular epithelium with varying degrees of dysplasia and foveolar hyperplasia was defined as an increased height of the pit with hyperchormatic nuclei and mitotic activity. The presence of intestinal metaplasia and gastric atrophy was also measured. In order to make the expression of each group represent that of each group, gastric mucosal scratches from five mice/group were mixed together and were homogenized in iced cold RIPA buffer. After fractionating in $4-12.5 \%$ SDS/PAGE, the proteins were transferred to nitrocellulose filters. The kinds of antibodies used for the current experiment were all purchased from Santa Cruz Biotechnology except pS2/TFF1 antibody, gift from Dr. G. Elia (Clone GE1, 31AA, London, UK). They were intercellular adhesion molecule-1 (ICAM-1), HCAM (CD44); a glycoprotein "homing receptor", transforming growth factor- $\beta 1$ (TGF- $\beta 1$ ); an anti-inflammatory cytokine, heat shock protein 70 (Hsp 70); molecular chaperon, MDM-2; a regulatory gene of $\mathrm{p} 53$, proliferating cell nuclear antigen (PCNA), Bcl-2, Bax, cyclooxygenase-2 (COX-2), h-met; a receptor molecule for hepatocyte growth factor, ornithine decarboxylase (ODC); a rate-limiting enzyme for gastric polyamine synthesis. The RPA is a highly sensitive and

Table 1. Incidence of glandular gastric tumors of mice according to group

\begin{tabular}{|c|c|c|c|c|}
\hline Group/Treatment & $\begin{array}{l}\text { Total No. of } \\
\text { mice }\end{array}$ & $\begin{array}{l}\text { Effective No. of } \\
\text { mice }\end{array}$ & $\begin{array}{c}\text { Dead No. of mice } \\
(\%)\end{array}$ & $\begin{array}{l}\text { No. of tumor bearing } \\
\text { mice (\% incidence) }\end{array}$ \\
\hline 2. HP alone & 20 & 19 & $1(5)$ & 0 \\
\hline 3. HP + Rebamipide & 20 & 20 & 0 & 0 \\
\hline 4. $\mathrm{MNU}+\mathrm{HP}$ & 20 & 17 & $3(15)$ & $11(64.7)$ \\
\hline 5. MNU alone & 20 & 19 & $1(5)$ & $2(10.5)^{*}$ \\
\hline 6. $\mathrm{MNU}+\mathrm{HP}+$ Rebamipide & 20 & 18 & $2(10)$ & $11(61.1)$ \\
\hline 7. $\mathrm{MNU}+\mathrm{HP}+\mathrm{NSD}$ & 20 & 18 & $2(10)$ & $7(38.9)^{* * *}$ \\
\hline
\end{tabular}

*Group 4 vs Group $5(\mathrm{p}<0.01)$

**Group 4 vs Group 7 ( $<<0.01)$

Table 2. Incidence of glandular gastric tumors by histologic findings

\begin{tabular}{lcccc}
\hline \multicolumn{1}{c}{ Group/Treatment } & $\begin{array}{c}\text { Effective No of } \\
\text { mice }\end{array}$ & $\begin{array}{c}\text { No. of Tumor } \\
\text { Bearing mice }\end{array}$ & $\begin{array}{c}\text { Adenoma } \\
(\%)\end{array}$ & \multicolumn{2}{c}{$\begin{array}{c}\text { Adenocarcinoma } \\
(\%)\end{array}$} \\
\hline 4. MNU $\rightarrow$ HP & 17 & $11(64.7)$ & $4(23.5)$ & $7(41.2)$ \\
5. MNU alone & 19 & $2(10.5)$ & $1(5.3)$ & $1(5.3)$ \\
6. MNU $\rightarrow$ HP + Rebamipide & 18 & $11(61.1)$ & $5(27.8)$ & $6(33.3)$ \\
7. MNU $\rightarrow$ HP + NSD & 18 & $7(38.9)$ & $6(33.3)$ & $1(5.6) *$ \\
\hline
\end{tabular}

*Group 4 vs Group 7 (p<0.01) 

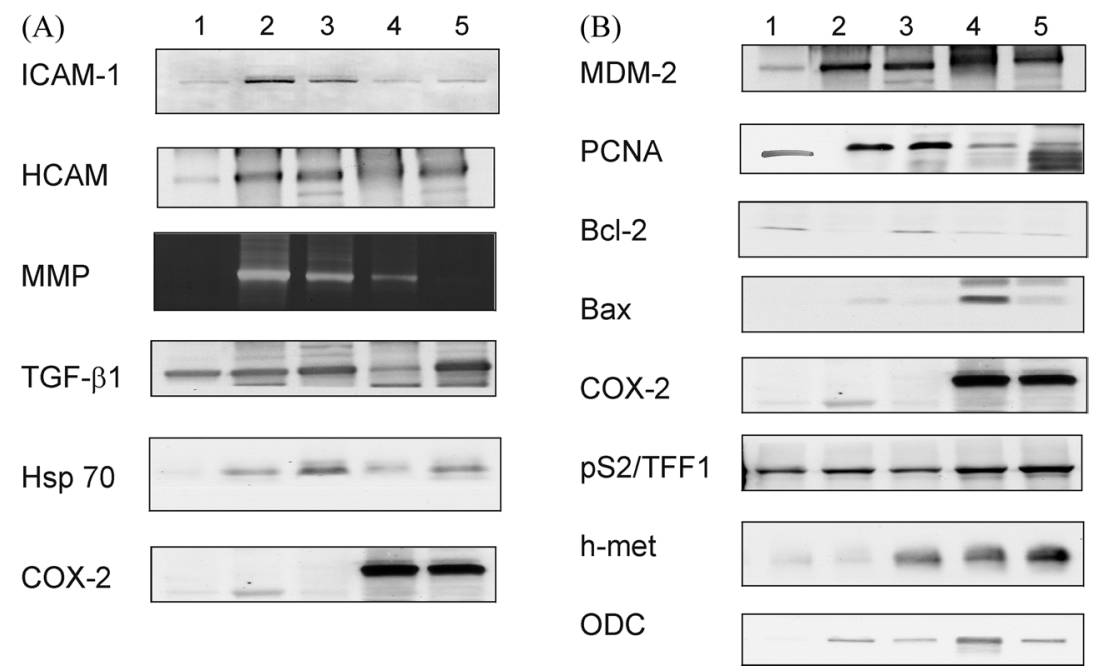

Fig. 3. Changes of protein profiles involved in (A) inflammation and (B) carcinogenesis. (A) Compared tothe normal controls, the $H$. pylori-infected stomach showed increased expressions of ICAM-1, HCAM, MMP, and Hsp70. Lane 3 (denotedH. pylori-infected mice that were administered with long-term rebamipide) showed the marked attenuation of ICAM-1 and MMP, and increased expressions ( TGF- $\beta 1$ and Hsp 70, more than lane 2 did, which signifies that the long-term administration of rebamipide decreased proteins, whic are involved in the propagation or perpetuation of inflammation. (B) The H. pylori infection increased the expressions of MDM-2 PCNA, and ODC. Compared to lane $4(\mathrm{MNU}+H$. pylori), lane $5(\mathrm{MNU}+$ H. pylori with long-term administration of rebamipide showed decreased expressions of MDM-2, PCNA, Bax, and ODC. On the other hand, the expressions of pS2/TFF1 and $h-m e t$ increased significantly more in lane 5 than in lane 4. Lane 1; Normal control, Lane 2;H. pylori alone, Lane 3; H. pylori + rebamipide, Lane 4; MNU $+H$. pylori, Lane 5; MNU $+H$. pylori + rebamipide.

specific method for the detection and quantitation of mRNA species. The probe used for RNase protection assay was synthesized using protocol provided with RiboQuant ${ }^{\circledR}$ in vitro transcription kit, using $100 \mathrm{mCi}$ of $800 \mathrm{Ci} / \mathrm{mmol}\left[\alpha_{-}{ }^{32} \mathrm{P}\right] \mathrm{UTP}$ and the probes purchased from PharMingen, named multiprobe RNase protection assay system. They used $\mathrm{mCK}-2$ containing interleukin-12p35 (IL-12p35), IL-12p40, IL-10, IL-1 $\beta$, IL- $1 \alpha$, monokine induced by IFN- $\gamma$ (MIG), IL- 6 , and interferon-gamma (IFN- $\gamma$ ), mCK-3 containing tumor necrosis factor-beta (TNF- $\beta$ ), lymphotoxin-beta (LT- $\beta$ ), TNF- $\alpha$, IL-6, IFN- $\beta$, IFN- $\alpha$, transforming growth factor-betal (TGF- $\beta 1$ ), TGF- $\beta 2$, mCK-5 containing lymphotactin (Ltn), Regulated on activation, normal T-cell expressed and secreted (RANTES), Eotaxin, macrophage inflammatory protein-one beta (MIP$1 \alpha$, MIP-1 $\beta$, MIP-2, IFN- $\gamma$ inducible protein 10 (IP-10), monocyte chemoattractant protein 1 (MCP-1), $\mathrm{T}$ cell activation protein-3 (TCA-3), mAPO-3 containing caspase-8, FasL, Fas, Fas-associated death domain (FADD), Fasassociated phosphatase (FAP), Fas-associated factor (FAF), TNF-related apoptosis inducing ligand (TRAIL), TNFRp55, TNFR1-associated death domain protein (TRADD), receptorinteracting protein (RIP).

Effect of the long-term administration of nimesulide or rebamipide on tumor incidence of mice The survival rate of each group was more than $85 \%$ and all animals in Group 3 survived until the 50th week (Table 1). The incidence of gastric tumors at the 50th week was $64.7 \%, 10.5 \%, 61.1 \%$, and $38.9 \%$ in Group 4, Group 5, Group 6, and Group 7, respectively, suggesting the significantly higher incidence of gastric tumors in mice treated with the combination of MNU and $H$. pylori infection and significantly lower incidence of gastric tumors in group co-treated with nimesulide. These results signified that $H$. pylori infection surely promoted MNU-induced gastric carcinogenesis and these promoting effect was abolished by COX-2 inhibitor. H. pylori alone (Group 2) or H. pylori administered with long-term rebamipide (Group 3) didnt develop any gastric tumors in mice model at 50 weeks. On the pathological evaluation of gastric tumors developed in Group 47 , gastric adenocarcinoma were noted in $41.2 \%$ of Group 4 , $5.3 \%$ of Group 5, 33.3 \% of Group 6, and 5.6\% of Group 7 (Table 2). No significant findings except chronic atrophic gastritis and foveolar hyperplasia were observed in Group 2 (50th week). This finding means that $H$. pylori infection might play a definite role as promoter in gastric carcinogenesis rather than direct carcinogen. Gastric adenomas showing proliferative immature glandular epithelium with varying degrees of dysplasia were frequently found in the groups treated with MNU and $H$. pylori infection, whereas gastric adenoma was observed in only one mouse of MNU alone. About two-thirds of adenocarcinoma was tubular adenocarcinoma and the remaining one-third was signet ring cell carcinoma. Most of the tumors (18/23) were found in the antrum. All these findings including gastric histopathologies were summarized in Fig. 7. In contrast to no significant pathological findings in uninfected mice, chronic atrophic gastritis and foveolar hyperplasia were seen in the mucosa of all H. pylori infected mice at the 50th week. In H. pylori-infected mice, marked infiltrations of 

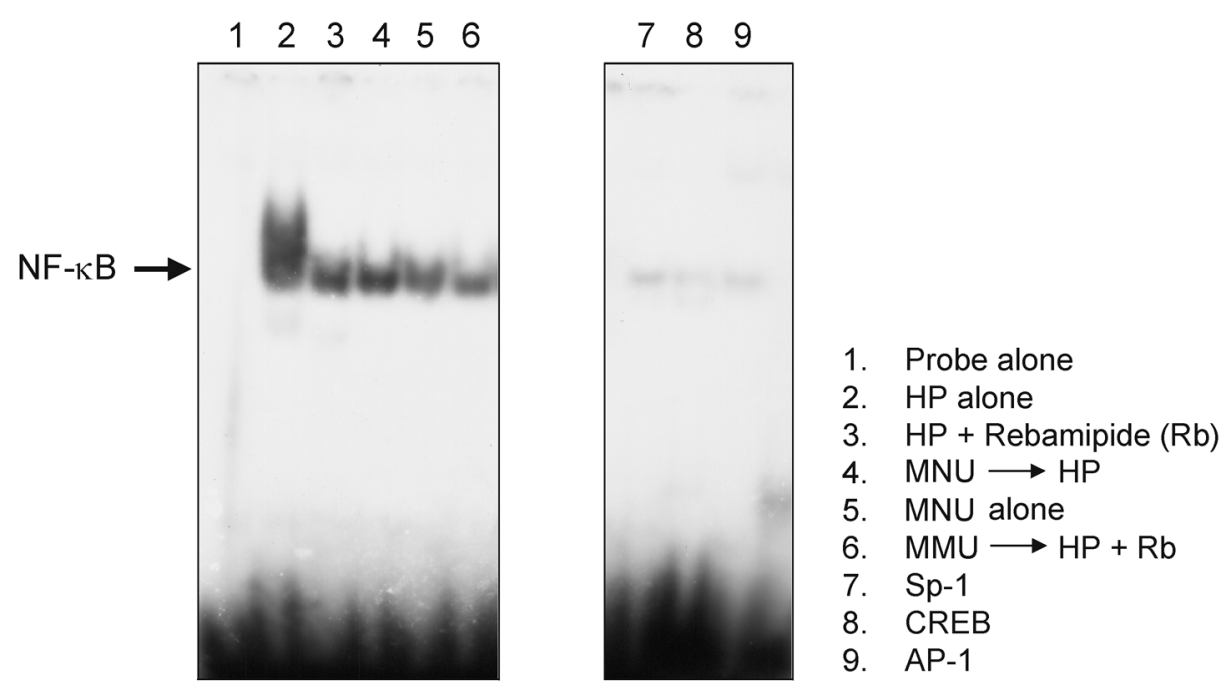

Fig. 4. Effects of long-term rebamipide on NF $\kappa B$ binding EMSA of the NF- $\mathrm{B}, \mathrm{Sp}-1, \mathrm{CREB}$, and AP-1 showed increased DNA bindings after the $\mathrm{H}$. pylori infection, more than the non-infected mice did (lane 1). The nuclear proteins of each lane were extacted from the three randomly-chosen-mice stomachs of each group, suggesting the EMSA band as the mean activity of each grou Treatment of rebamipide (lanes $3 \& 6$ ) significantly decreased NFKB-DNA binding, more than did lanes 1 or $4 / 5$.

lymphocyte, plasma cells, and neutrophils and eosinophils with lesser frequency were present in the lamina propria and submucosa and formations of lymphoid follicles. Interestingly, Group 6, HPR, and Group 7, HPN, showed marked low incidence of atrophic gastritis compared to Group 4, $\mathrm{MNU}+H$. pylori, suggesting long-term rebamipide or nimesulide administration reduced the development of chronic atrophic gastritis and intestinal metaplasia (data not shown).

Effects of the long-term administration of rebamipide on the expressions of various gastric proteins We divided the various proteins tested into two groups based on their implication of action, inflammation related proteins (Fig. 3A) and cell growth related proteins (Fig. 3B). After $H$. pylori infection, ICAM-1, HCAM (CD44), MMP, COX-2, and Hsp 70 were induced or increased definitely (lane 2 in Fig. 3A and $3 \mathrm{~B})$. On the other hand, long-term administration of rebamipide mixed in pellet diets caused the attenuation of the expressions of ICAM-1, HCAM , MMP and increased the expressions of Hsp 70 (lane 3 in Fig. 3A and 3B). These results suggested the excellent actions of rebamipide in either decreasing the proteins involved in the propagation and aggravation of gastric inflammation or increasing cytoprotective protein. TGF- $\beta 1$, well-known antiinflammatory cytokine, was modestly increasingly expressed in Group 6, $\mathrm{MNU}+H$. pylori + rebamipide. $\mathrm{COX}-2$ expression was not prominent irrespective of rebamipide or $H$. pylori, but significantly increased after $\mathrm{MNU}+H$. pylori group. In group 4, MNU $+H$. pylori, ornithine decarboxylase (ODC), Bax, pS2/TFF1 (trefoil peptide protein), $h$-met, and COX-2 were significantly increasingly induced, suggesting the increased cellular proliferations, but the levels of expression of ODC, COX-2, PCNA were significantly decreased after the further chronic administration of rebamipide. $\mathrm{pS} 2 / \mathrm{TFF} 1$, a tumor suppressor protein specially engaged in gastric carcinogenesis, was slightly increasingly expressed after lon-term administration of rebamipide.

Effects of the long-term administration of rebamipide on NF- $\kappa$ B binding Fig. 4 showed the NF- $\kappa B$ complex of nuclear proteins extracted from each group detected by electrophoretic mobility shift assay. The nuclear proteins were extracted from the three randomly selected mice stomach of each group, suggesting the EMSA band as the mean activities of each group. H. pylori infection (lane 2) increased NF-KBDNA binding significantly than non-infected group (lane 1). However, treatment of rebamipide decreased NF- $\kappa \mathrm{B}$ binding significantly ( $16.6 \%$ of lane 2 ). In a point of NF-KB-DNA binding, administration of MNU only caused slight increment of NF- $\mathrm{KB}$ binding irrespective of $H$. pylori infection, but lane 6 , group treated with rebamipide also attenuated the NF- $\kappa \mathrm{B}$ binding than MNU and $H$. pylori group (lane 5), suggesting the possible actions of rebamipide on modulating the inflammatory response through transcriptional regulation of NF-kB.

Effects of the long-term administration of rebamipide on mRNA of cytokines and apoptosis-related genes We investigated the various mRNA transcripts of mouse cytokines and chemokines by multi-probe RNase protection assay. Fig. 5A showed the RPA of mCK-3 (RiboQuant ${ }^{\circledR}$, multi-probe RPA) showing TNF- $\beta$, LT $\beta$, TNF- $\alpha$, IL-6, IFN- $\gamma$, IFN- $\beta$, TGF- $\beta 1$, TGF- $\beta 2$. Among them TNF- $\beta$, LT $\beta$, TNF- $\alpha$, IL-6 and IFN- $\gamma$ were increased after chronic $H$. pylori infection. After long-term administration of rebamipide, all of these transcripts were significantly decreased (lane 2 vs lane 3 ). No 
(A)

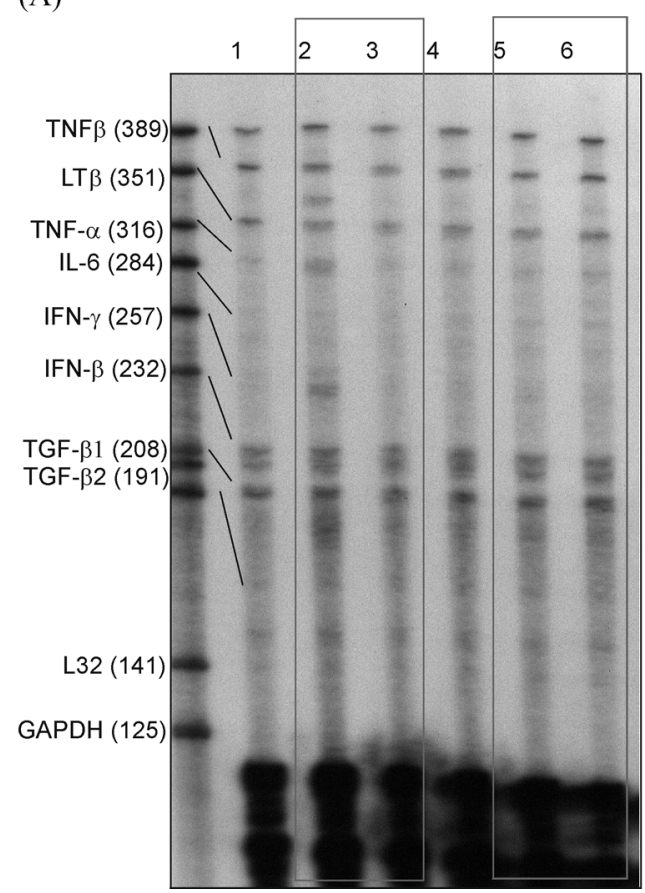

(B)

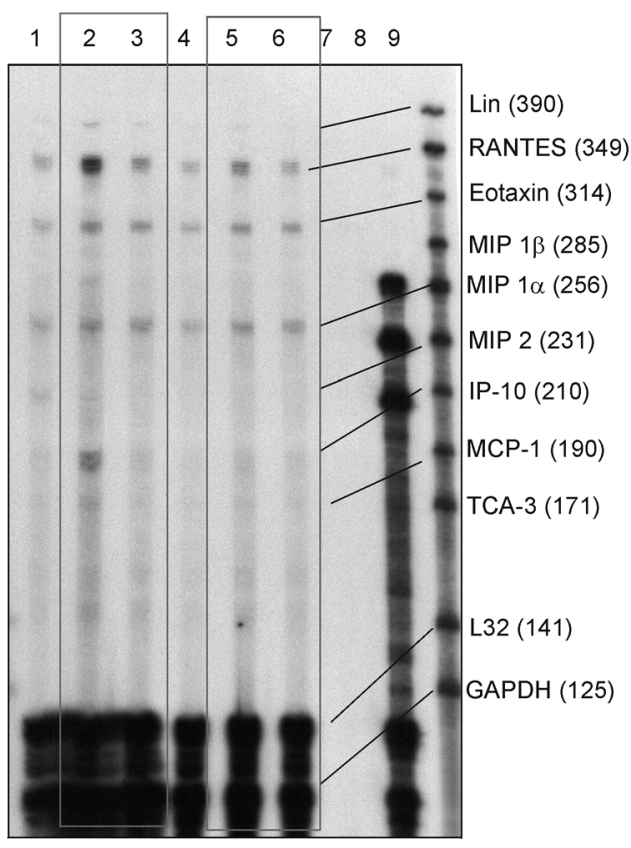

Fig. 5. Effects of long-term rebamipide on mRNA of cytokines genes (A) Multi-probe RPA of mouse cytokines [mCK-3 kit (RiboQuant ${ }^{\circledR}$, PharMingen Cat \# 45003p)] contained TNF- $\beta$, LT $\beta$, TNF- $\alpha$, IL-6, IFN- $\gamma$, IFN- $\beta$, TGF- $\beta 1$, and TGF- $\beta 2$. Among them, TNF- $\beta$, LT $\beta$, TNF- $\alpha$, IL- 6 , and IFN- $\gamma$ increased after chronic $H$. pylori infection, which was significantly decreased after the long-term administration of rebamipide. (B) Multi-probe RPA of mouse cytokines [mCK-5 kit (RiboQuant ${ }^{\circledR}$, Cat \# 45026p)] RPA of mCK-5 displayed chemokines, like Ltn, RANTES, Eotaxin, MIP-1 $\beta$, MIP-1 $\alpha$, MIP-2, IP-10, MCP-1, and TCA-3. Similar to (A), the H. pylori infection increased all of these chemokines mRNA, except MIP-2 and TCA-3. The long-term administration of rebamipide showed remarkable decreases in the mRNA of RANTES, Lin, and IP-10. Lane 1; Normal control, Lane 2; H. pylori alone, Lane 3; H. pylori + rebamipide, Lane 4, MNU alone, Lane 5; MNU + H. pylori, Lane 6; MNU + H. pylori + rebamipide, Lane 7; Yeast RNA, Lane 8; Control RNA, Lane 9; Size markers.

significant change was noted in MNU treated group irrespective of rebamipide administration. Fig. 5B showed the RPA of mCK-5 showing chemokines like Ltn, RANTES, Eotaxin, MIP-1 $\beta$, MIP-1 $\alpha$, MIP-2, IP-10, MCP-1, TCA-3. Similar to cytokines, $H$. pylori infection increased all of these chemokines except MIP-2 and TCA-3. Long-term administration of rebamipide showed remarkable decreases in transcript levels of RANTES, Lin, and IP-10 in MNU treated group, rebamipide decreased RANTES, eotaxin, and MIP- $1 \alpha$. Fig. 6 showed the RPA of mAPO-3 containing caspase-8, FasL, Fas, FADD, FAP, FAF, TRAIL, TNFRp55, TRADD, RIP. $H$. pylori infection increased the genes involved in apoptosis. Slight decreases in transcript of caspase-8, FasL, Fas and TRAIL were observed in long-term administration of rebamipide pretreated with MNU.

\section{Chemoprevention of Helicobacter pylori-associated Gastric Carcinogenesis in Mice Model; Is It Possible?}

Our above described study showed nimesulide, preferred COX-2 inhibitor, resulted in significant decrease in $H$. pylori- associated gastric carcinogenesis and rebamipide, anti-ulcer and anti-inflammatory drug, showed significant attenuating effects in the severity of $H$. pylori-associated gastritis, based on the findings that rebamipide decreased cell adhesion molecule, ICAM-1 and HCAM, reduced MMP activities, decreased COX-2 expressions, reduced the DNA binding of inflammation-associated transcription factor, NF- $\mathrm{BB}$, decreased cytokine activities like IL-1 $\beta$, TNF- $\alpha$, RANTES, IP-10, MIP-1 $\alpha$, and IFN- $\gamma$.

Long-term administration of nimesulide showed significant strong chemopreventive actions against $H$. pylori-associated gastric carcinogenesis and halted the progress from gastric adenoma to gastric cancer. These results might be ensuied from the blockade of COX-2 in the progression of adenomatous growth. Whereas, the long-term administration of rebamipide did not show the definite evidence of chemoprevention in spite of excellent anti-inflammatory action, which could be explained by the fact that rebamipide maintained the balance between cell proliferation and apoptosis, since apoptosis must exceed cell proliferation in order to achieve chemoprevention (Moss, 1998). However, the development of precancerous lesion like chronic atrophic gastritis was surely retarded and decreased by the long-term 


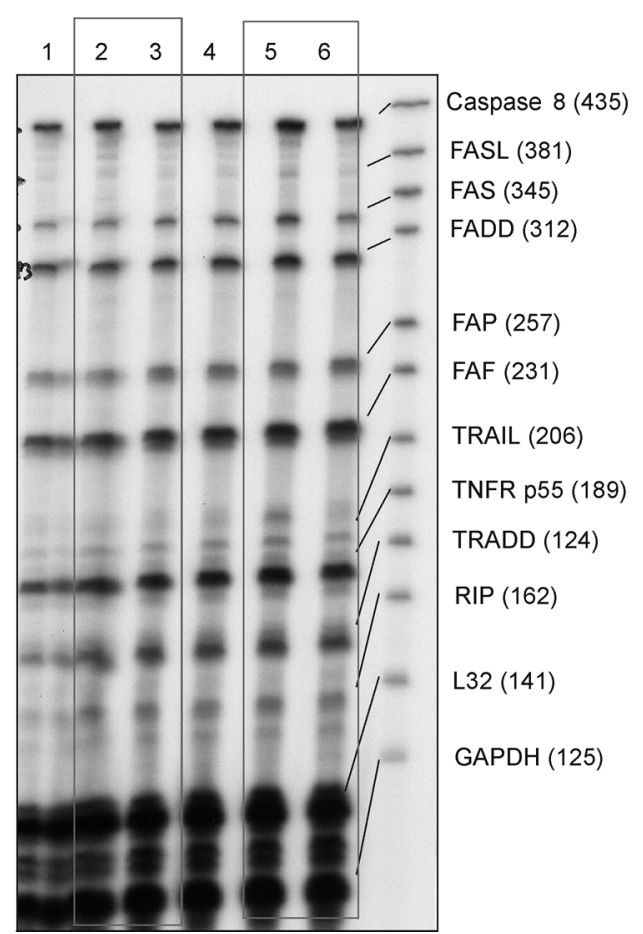

1. Normal control

2. HP alone

3. $\mathrm{HP}+$ Rebamipide $(\mathrm{Rb})$

4. $\mathrm{HP} \longrightarrow \mathrm{MNU}$

5. $\mathrm{MMU} \longrightarrow \mathrm{HP}$

6. $\mathrm{MMU} \longrightarrow \mathrm{HP}+\mathrm{Rb}$

Fig. 6. Effects of long-term administration of rebamipide on mRNA of apoptosis-related genes. RPA of mAPO-3 (RiboQuant ${ }^{2}$, Cat \#45355p) dealt with caspase-8, FasL, Fas, FADD, FAP, FAF, TRAIL, TNFRp55, TRADD, and RIP. The H. pylori infection increased the genes that were involved in apoptosis. Slight decreases in the transcript of caspase- 8 , FasL, Fas and TRAIL were observed in the long-term administration of rebamipide that was pretreated with MNU. Lane 1; Normal control, Lane 2; H. pylori alone, Lane 3; $H$. pylori + rebamipide, Lane 4, MNU alone, Lane 5; MNU + H. pylori, Lane 6; MNU + H. pylori + rebamipide.

administration of rebamipide.

The study described in the above section might be the first study showing the chemoprevention of nimesulide or rebamipide in $H$. pylori-infected animal model (Fig. 7). Before this, there was rat model with chronic gastritis developed by the continuous administration of $5 \mathrm{mM}$ sodium taurocholate for six months. Rebamipide treatment for four weeks (6 and $60 \mathrm{mg} / \mathrm{kg} /$ day) initiated after development of chronic gastritis dose-dependently attenuates the gastritis in terms of degree of inflammatory cell infiltration, erosions, and glandular atrophy (Kishimoto, 1992). Proposed mechanisms for anti-inflammatory and mucosal protective actions of rebamipide were decreased neutrophilic activitity (Suzuki et al., 1994), decreased production of inflammatory cytokines (Aihara et al., 1998), and decreased generations of oxygen free radicals (Iinuma et al., 1998). Chemoprevention by NSAIDs was only tried in familial adenomatous polyposis and colon cancer model. Chemoprevention trials in gastric carcinogenesis and even $H$. pylori-association were not reported at all before the current trial except in vitro evidence of retinoic acids in the cytotoxicity of gastric cancer cells. Recently Steinbach et al. (2000) reported the definite advantage of celecoxib, a specific COX-2 inhibitor, in preventing the development of colonic adenomatous polyposis in familial adenomatosis polyposis patients. The exact underlying molecular mechanisms how nimesulide showed the significant chemopreventive actions are under investigation. Instead, in the current study, data about the molecular actions of another antiinflammatory drug used in the current study, rebamipide, were revealed.

Since $H$. pylori generally adhered to gastric epithelial cells without invading the epithelium, it is presumed that an interaction between bacteria and host epithelia cells may initiate H. pylori-induced inflammation (Ernst et al., 1997). Because of the strong inflammatory response to $H$. pylori infections, the role of inflammatory cytokines has been investigated and it was shown that mucosal biopsy specimens from patients with $H$. pylori infection contain significantly elevated levels of IL-1 $\beta$, IL-6, TNF- $\alpha$, and IL- 8 compared to those in specimens from uninfected individuals (Crabtree, 1991; Rieder et al., 1997; Yamaoka et al., 2001). Most intracellular bacteria generally induce Th1 responses, while extracellular pathogens stimulate Th2 responses. Based on the fact that $H$. pylori are non-invasive and that infection is accompanied by an exuberant humoral response, one might predict that a Th2 response would be predominant within $H$. pylori-colonized gastric mucosa. Paradoxically, the majority of $H$. pylori antigen-specific T-cell clones isolated from infected gastric mucosa produce higher levels of IFN- $\gamma$ than IL-4 or IL-10, which is reflective of a Th1 type response (Bamford et al., 1998). Therefore, certain strains of mice (C57BL/6) infected with $H$. felis that develop a Th1 type 


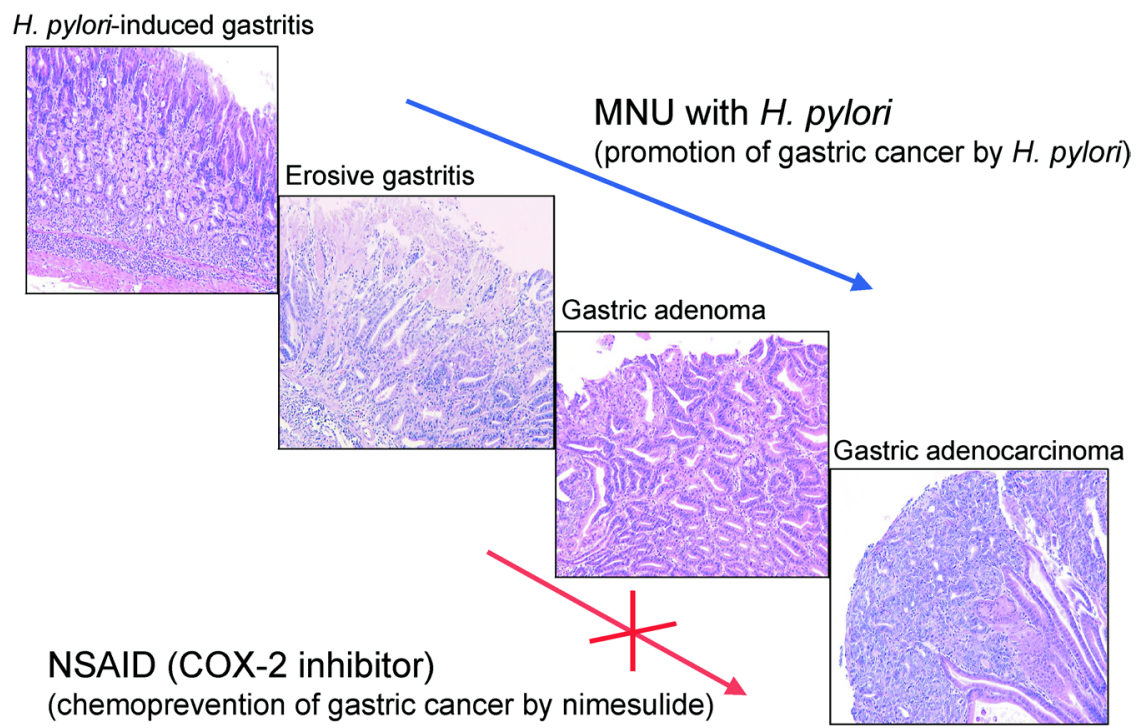

Fig. 7. Pathological changes after MMU administrations and $H$. pylori infection. Serial changes of gastritis were observed after the $H$. pylori infection in mice. MNU and $H$. pylori infection promoted the development of gastric adenoma and adenocarcinoma. Without the $H$. pylori infection after the MNU administration, the pathologies remained as chronic atrophic or hypertrophic gastritis as far as the lifespan of mice. Nimesulide administration blocked the progression of gastric adenoma to gastric adenocarcinoma, and rebamipide administration decreased the development of precanceous lesions like chronic atrophic gastritis in mice. Photography $(\times 100$ magnification)

response exhibit extensive gastric inflammation, while other genetically distinct strains $(\mathrm{BALB} / \mathrm{c})$ that respond to infection with a Th2-like response develop only minimal gastritis (Sakagami et al., 1996). Adoptive transfer of Th2 lymphocytes from infected mice into infected recipients reduces bacterial colonization density, while transfer of Th1 cells increases the severity of gastritis (Mohammadi et al., 1997). In the current experiment, we could confirm that definite Th1 type response was generated by $H$. pylori infection and long-term administration of rebamipide, antiinflammatory drug, attenuated Th1 type cytokine generations and increased Th2 type cytokine, which led to decreased gastric inflammation in final.

Cell-cell interactions play an important and probably central role in a large number of immunological processes in physiological and pathological conditions. These interactions are at least partially mediated by various cell adhesion molecules. Expression of cell adhesion molecules on gastric epithelial cells may participate in leukocyte homing and epithelial cell adhesions in $H$. pylori-associated mucosal inflammations (Mori et al., 2000). In the context of H. pylori infection, the production of chemoattractive cytokines and cell adhesion molecules could provide a means of recruiting and retaining inflammatory cells within gastric epithelial cells, contributing to $H$. pylori-mediated tissue injury. Co-culture of epithelial cells with cytotoxin-associated gene pathogenicity island-positive (cag PAI+) H. pylori strains, but not with a cag PAI- strain resulted in up-regulation of steady-state mRNA levels and cell surface expressions of ICAM-1. H. pylori activated the ICAM-1 or IL-8 promoter via the NF- $\mathrm{KB}$ binding site (Keates et al., 1997). In the current study, long- term administration of rebamipide showed the advantage of decreasing ICAM-1 and even HCAM.

The finding that $H$. pylori is a potent activator of NF- $\mathrm{KB}$ has important implications, since other $\mathrm{NF}-\kappa \mathrm{B}$ responsive genes, including those encoding IL-8, TNF- $\alpha$, IL-1, and IL-6, has been found to be elevated in the gastric mucosa of persons with H. pylori (Crabtree et al., 1991; Sakagami et al., 1996; Ernst et al., 1997; Keates et al., 1997; Mohammadi et al., 1997; Rieder et al., 1997; Aihara et al., 1998; Bamford et al., 1998; Iinuma et al., 1998; Sharma, 1998; Mari et al., 2000; Yamaoka et al., 2001). NF- $\kappa \mathrm{B}$ is well recognized as a redoxsensitive transcription factor and has been implicated in the cellular response to oxidative stress. Nearly all the inflammatory pathways leading to NF- $\kappa \mathrm{B}$ activation could be blocked by a variety of antioxidants, including N-acetyl-Lcystein, glutathione, thioredoxin, pyrrolidine dithiocarbamate or by over-expression of antioxidant enzymes (Schreck, 1992;

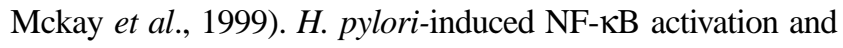
the subsequent up-regulation of cytokines could contribute to inflammatory cell recruitment and retention at sites of infection. Because of its pivotal role in inflammation, NF- $\kappa B$ will be an obvious target for new types of anti-inflammatory treatments for $H$. pylori-induced gastritis (Mori et al., 2000). In the current experiment, long-term administration of rebamipide in $H$. pylori infection significantly attenuated the participation of NF- $\kappa$ B-DNA binding, which resulted in reducing the cytokines involved in $H$. pylori-associated gastric inflammation.

H. pylori infection is associated with elevated levels of both mucosal apoptosis and proliferation. The initiation and the regulation of the pathways that promote these paradoxical 
Perspective of chemoprevention in $\mathrm{H}$. pylori -associated gastric cancer

\section{Anti -inflammatory drugs can do chemoprevention Combination with COX-2 inhibitor}

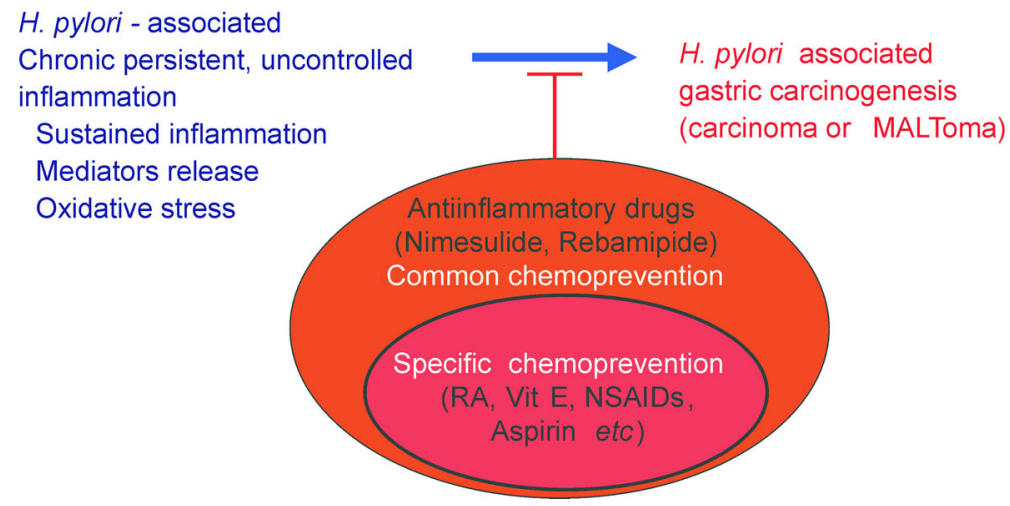

Fig. 8. Perspective of chemoprevention in H. pylori-associated gastric cancer by nimesulide or rebamipide. Retinoic acids or rexinoids are well-known chemopreventive drugs in various cancers, like leukoplakia, breast cancer, and aerodigestive tumors. According to the results in the current study, the long-standing administration of anti-inflammatory drugs like nimesulide or rebamipide could be classified as common chemoprevention since these drugs surely retarded the development of $H$. pylori-associated gastric carcinogenesis in the mice model.

cellular responses are still unclear. However, the any disturbances in maintaining this homeostasis between apoptosis and proliferation could result in definite clinical outcome like peptic ulcer disease or gastric cancer (Asaka, 1998; Moss, 1998; Konturek et al., 2001). Fas Ag, which is a transmembrane receptor, which when bound specifically to its ligand (FasL) trimerizes and initiates a cascade of events resulting in apoptosis. By the way, Fas Ag and Fas L expression had been shown to be regulated at the mRNA level in $H$. pylori-induced gastritis by inflammatory cytokines such as IL-1 $\beta$, TNF- $\alpha$, and IFN- $\gamma$ (Jones et al., 1999).

Although there have been several reports showing the increased mucosal inflammatory cytokines, including IL-1 $\beta$, IL-6, IL-8, TNF- $\alpha$, and IFN- $\gamma$ in cells or human tissue homogenates of $H$. pylori-associated gastritis (Peek et al., 1995), current study might be the first report revealing the real evidence of the activation of these genes in mouse model of $H$. pylori infection and the attenuation of these cytokines by the long-term administration of anti-inflammatory and radical scavenging drug, rebamipide. According to RNase protection assay of current study, surely $H$. pylori infection increased apoptosis-related genes, caspase-8, Fas Ag, Fas L, FAF, and TRADD, but there were no definite changes of apoptosisrelated genes by rebamipide treatment. In mice model of MNU and $H$. pylori administration, rebamipide reduced Fas L and Fas mRNA. We inferred that failure of definite chemopreventive effect of rebamipide could be explained by the maintenance of cell proliferation in spite of long-term rebamipide administration, suggesting the requirement of another apoptosis inducing drug to achieve chemopreventive effect of rebamipide. According to the report by Wang et al.
(2000), gastric T cells contribute to apoptosis of the epithelium by a Fas/FasL interaction, which was increasingly expressed during infection with $H$. pylori. In the current experiment, clear decrement of Fas/FasL mRNA was observed in rebamipide administration, but this result was from the total RNA extracted of whole gastric mucosal scratches, not of mucosal T cells.

The natural history of $H$. pylori-associated gastritis is an inexorable progression involving more and more of the stomach, ultimately leading to gastric atrophy (Go, 2000). In general, this process is slow, requiring between 20 and 40 years to complete (Uemura et al., 2001). Atrophic gastritis is widely considered to be a precursor lesion of the intestinal type of gastric cancer (Asaka et al., 1997). A multi-step model for the development of gastric cancer has been proposed beginning with a histological diagnosis of superficial gastritis, which then progressed to chronic atrophic gastritis, followed by intestinal metaplasia, and ultimately, dysplasia (Correa, 1995). In the study shown above, long-term administration of nimesulide or rebamipide resulted in reduced development of chronic atrophic gastritis compared to non-treated group. Although long-term rebamipide administration did not achieve the reduction of gastric carcinogenesis developed by $H$. pyloris promoting carcinogenesis of MNU administration, significant reduction in the expression of MDM-2, "big brother" of p53 (Momand et al., 1996), and ODC, accelerator for cell growth (Mori et al., 1996) and significant elevation of pS2/TFF1, possible tumor suppressor protein (Lefebvre et al., 1996), were reached, suggesting the potential implication of rebamipide should be considered as ultimate chemoprevention protocol for gastric carcinogenesis. 


\section{The Perspective of Chemoprevention of H. pylori-associated Gastric Carcinogenesis}

Many evidences suggest that $H$. pylori surely caused gastric malignancies including adenocarcinoma and lymphoma (Uemura et al., 2001). H. pylori provoked acute and chronic gastritis, chronic atrophic gastritis, and gastric adenoma, by which WHO-IARC defined $H$. pylori as class I carcinogen. By the way, since $H$. pylori can be removed by medications composing of one or two weeks of triple drug regimen including proton pump inhibitor and antibiotics, chemoprevention of gastric carcinoma could be possible, if we can definitely confirm the mechanistic links between $H$. pylori infection and gastric cancer. Although our current trial that the long-term administration of anti-inflammatory drugs, nimesulide or rebamipide, showed either the excellent antiinflammatory effects and partial anti-proliferative effects or definite chemopreventive effects in $H$. pylori infection, but further clinical trials will be required to draw the definite clinical advantage of the longterm administration of antiinflammatory drugs, nimesulide or rebamipide or both (Fig. 8). Molecular biological data surely support the potentiality of longterm administration of nimesulide or rebamipide on chemoprevention. The next step for the chemoprevention of $H$. pylori-associated gastric carcinogenesis will be to prove the concrete clinical advantage of prescribing the anti-inflammatory drugs or eradicating $H$. pylori in the clinical field.

Acknowledgments This work was supported by a grant of the Korea Health 21 R \& D project, Ministry of Health and Welfare, Republic of Korea (Project No. 01-PJ10-PG601GN14-0007) and is one of the MAGIC project researches.

\section{References}

Aihara, M., Imagawa, K., Funakoshi, Y., Ohmoto, Y. and Kikuchi, M. (1998) Effects of rebamipide on production of several cytokines by human peripheral blood mononuclear cells. Dig. Dis. Sci. 43, 160S-166S.

Arakawa, T., Kobayashi, K., Yoshikawa, T. and Tarnawski, A. (1998) Rebamipide: overview of its mechanisms of action and efficacy in mucosal protection and ulcer healing. Dig. Dis. Sci. 9, 5S-13S.

Asaka, M., Takeda, H., Sugiyama, T. and Kato, M. (1997) What role does Helicobacter pylori play in gastric cancer? Gastroenterology 113, S56-S60.

Asaka, M., Kudo, M., Kato, M., Sugiyama, T. and Takeda, H. (1998) Long-term Helicobacter pylori infection from gastritis to gastric cancer. Aliment Pharmacol. Ther. 12, Suppl. 9-15.

Bamford, K. B., Fan, X., Crowe, S. E., Leary, J. F., Gourley, W. K., Luthra, G. K., Brooks, E. G., Graham, D. Y., Reyes, V. E. and Ernst, P. B. (1998) Lymphocytes in the human gastric mucosa during Helicobacter pylori have a $\mathrm{T}$ helper cell 1 phenotype. Gastroenterology 114, 482-492.

Baik, S. C., Youn, H. S., Chung, M. H., Lee, W. K., Cho, M. J.,
Ko, G. H., Kasai, H. and Rhee, K. H. (1996) Increased oxidative DNA damage in Helicobacter pylori-infected human gastric mucosa. Cancer Res. 56, 1279-1282.

Bechi, P., Balzi, M., Becciolini, A., Maugeri, A., Raggi, C. C., Amorosi, A. and Dei, R.. (1996) Helicobacter pylori and cell proliferation of the gastric mucosa: possible implications for gastric carcinogenesis. Am. J. Gastroenterol. 91, 271-276.

Correa, P. (1995) Helicobacter pylori and gastric carcinogenesis. Am. J. Surg. Pathol. 19, 37-43.

Crabtree, J. E., Shallcross, T. M., Heatley, R. V. and Wyatt, J. I. (1991) Mucosal tumor necrosis factor alpha and interleukin-6 in patients with Helicobacter pylori-associated gastritis. Gut 32, 14730-1477.

Davis, R. and Brogden, R. N. (1994) Nimeulide; An update of its pharmacodynamic and pharmacokinetic properties, and therapeutic efficacy. Drug 48, 431-454.

Ernst, P. (1999) The role of inflammation in the pathogenesis of gastric cancer. Aliment Pharmacol. Ther. 13, 13-18.

Ernst, P. B., Crowe, S. E. and Reyes, V. E. (1997) How does Helicobacter pylori cause mucosal damage? The inflammatory response. Gastroenterology 113, S35-S42.

Go, M. F. (1997) What are the host factors that place an individual at risk for Helicobacter pylori-associated disease? Gastroenterology 113, 15-20.

Go, M. F. (2000) Natural history and epidemiology of Helicobacter pylori infection. Aliment Pharmacol. Ther. 16, 315.

Hahm, K. B., Lee, K. J., Choi, S. Y., Kim, J. H., Cho, S. W., Yim, H., Park, S. J. and Chung, M. H. (1997) Possibility of chemoprevention by the eradication of Helicobacter pylori: oxidative DNA damage and apoptosis in H. pylori infection. Am. J. Gastroenterol. 92, 1863-1857.

Han, B. G., Kim, H. S., Rhee, K. H., Han, H. S. and Chung, M. H. (1995) Effects of rebamipide on gastric cell damage by Helicobacter pylori-stimulated human neutrophils. Pharmacol. Res. 32, 201-207.

Han, S. U., Kim, Y. B., Joo, H. J., Hahm, K. B., Lee, W. H., Cho, Y. K., Kim, D. Y. and Kim, M. W. (2002) Helicobacter pylori infection promotes gastric carcinogenesis in a mice model. $J$. Gastroenterol. Hepatol. 17, 253-261.

Iinuma, S., Naito, Y., Yoshikawa, T., Takahashi, S., Takemura, T., Yoshida, N. and Kondo, M. (1998) In vitro studies indicating antioxidative properties of rebamipide. Dig. Dis. Sci. 43, 35S39S.

Israel, D. A. and Peek, R. M. (2001) Pathogenesis of Helicobacter pylori-induced gastric inflammation. Aliment Pharmacol. Ther. 15, 1271-1290.

Jacoby, R.F., Seibert, K., Cole, C.E., Kelloff, G. and Lubet, R.A. (2000) The cyclooxygenase-2 inhibitor celecoxib is a potent preventive and therapeutic agent in the Min mouse model of adenomatosis polyposis. Cancer Res. 40, 5040-5044.

Jones, N. L., Day, A. S., Jennings, H. A. and Sherman, P. M. (1999) Helicobacter pylori induces gastric epithelial cell apoptosis in association with increased Fas receptor expression. Infect. Immun. 67, 4237-4242.

Keates, S., Hitti, Y. S., Upton, M. and Kelly, C. P. (1997) Helicobacter pylori infection activates NF-kappa B in gastric epithelial cells. Gastroenterology 113, 1099-1109.

Kishimoto, S. (1992) Therapeutic effects of oral rebamipide and in combination with cimetidine on experimental gastritis in rats. 
Res. Commun. Chem. Pathol. Pharmacol. 78, 259-277.

Konturek, P. C., Konturek, S. J., Pierzxhalski, P., Bielanski, W., Duda, A., Marlicz, K., Starzynska, T. and Hahn, E. G. (2001) Cancerogenesis in Helicobacter pylori infected stomach role of growth factors, apoptosis, and cyclooxygenases. Med. Sci. Monit. 7, 1092-1107.

Lefebvre, O., Chenard, M. P., Masson, R., Linares, J., Dierich, A., LeMeur, M., Wendling, C., Tomasetto, C., Chambon, P. and Rio, M. C. (1996) Gastric mucosal abnormoalities and tumorigenesis in mice lacking the pS2 trefoil protein. Science 274, 259-262.

Mai, U. E., Perez-Perez, G. L., Allen J. B., Wahl, S. M., Blaser, M. J. and Smith, P. D. (1992) Surface proteins from Helicobacter pylori exhibit chemotactic activity for human leukocytes and are present in gastric mucosa. J. Exp. Med. 175, 517-525.

Mckay, L. I. and Cidlowski, J. A. (1999) Molecular control of immune/inflammatory response; Interactions between nuclear factor- $\mathrm{KB}$ and steroid receptor-signaling pathway. Endocr. Rev. 20, 435-459.

Mohammadi, M., Czinn, S., Redline, R., Lycke, N. and Czinn, S. J. (1997) Murine CD4 T-cell response to Helicobacter infection: Th1 cells enhance gastritis and Th2 cells reduce bacterial load. Gastroenterology 113, 1848-1857.

Momand, J. and Zambetti, G. P. (1997) MDM-2: "big brother" of p53. J. Cell. Biochem. 64, 343-352.

Mori, M., Honda, M., Shibuta, K., Baba, K., Nakashima, H., Haraguchi, M., Koba, F., Ueo, H., Sugimachi, K. and Akiyoshi, T. (1996) Expression of ornithine decarboxylase mRNA in gastric carcinoma. Cancer 77, 1634-1638.

Mori, N., Wada, A., Hirayama, T., Parks, T. P., Stratowa, C. and Yamamoto, N. (2000) Activation of intercellular adhesion molecule 1 expression by Helicobacter pylori is regulated by $\mathrm{NF}-\mathrm{\kappa B}$ in gastric epithelial cancer cells. Infect. Immun. $\mathbf{6 8}$, 1806-1814.

Moss, S. F., Calam, J., Agarwal, B., Wang, S. and Holt, P. R. (1996) Induction of gastric epithelial apoptosis by Helicobacter pylori. Gut 38, 498-501.

Moss, S. F. (1998) Cellular markers in the gastric precancerous process. Aliment Pharmacol. Ther. 12, 91-109.

Moss, S. F., Legon, S., Davies, J. and Calam, J. (1994) Cytokine gene expression in Helicobacter pylori associated antral gastritis. Gut 35, 1567-1570.

Peek, R. M., Miller, G. G., Tham, K. T., Perez-Perez, G. I., Zhao, X., Atherton, J. C. and Blaser, M. J. (1995) Heightened inflammatory response and cytokine expression in vivo to cag $\mathrm{A}^{+}$Helicobacter pylori strains. Lab. Invest. 73, 760-770.

Peek, R. M., Moss, S. F., Tham, K. T., Perez-perez, G. I., Wang, S., Miller, G. G., Atherton, J. C., Holt, P. R. and Blaser, M. J. (1997) Helicobacter pylori cag $\mathrm{A}^{+}$strains and dissociation of gastric epithelial cell proliferation from apoptosis. J. Natl. Cancer Inst. 89, 863-868.

Rautelin, H., Blomberg, B., Jarnerot, G. and Danielsson, D. (1994) Nonopsonic activation of neutrophils and cytotoxin production by Helicobacter pylori: ulcerogenic markers. Scand. J. Gastroenterol. 29, 128-132.

Reddy, B, Rao, C. V. and Seibert, K. (1996). Evaluation of cyclooxygenase-2 inhibitor for potential chemopreventive properties in colon carcinogenesis. Cancer Res. 56, 4566-4569.

Rieder, G., Hatz, R. A., Moran, A. P., Walz, A., Stolte, M. and
Enders, G. (1997) Role of adherence in interleukin-8 induction in Helicobacter pylori-associated gastritis. Infect. Immun. 65, 3622-3630.

Sakagami, T., Dixon, M., ORourke, J., Howlett, R., Alderuccio, F., Vella, J., Shimoyama, T. and Lee, A. (1996) Atrophic gastric changes in both Helicobacter felis and Helicobacter pylori infected mice are host dependent and separate from antral gastritis. Gut 39, 639-648.

Schreck, R., Albermann, K. and Baeuelre, P. A. (1992) Nuclear factor kappa B: an oxidative stress response transcription factor of eukaryotic cells. Free Radic. Res. Commun. 17, 221-227.

Sharma, S. A., Tummuru, M. K., Blasér, M. J. and Kerr, L. D. (1998) Activation of IL-8 gene expression by Helicobacter pylori is regulated by trabnscription factor nuclear factor-kappa B in gastric epithelial cells. J. Immunol. 160, 2401-2407.

Steinbach, G., Lynch, P., Phillips, R., Wallace, M. H., Hawk, E., Gordon, G. B., Wakagayashi, N., Saunders, B., Shen, Y., Fujimura, T., Su, L. and Levin, B. (2000) The effect of celecoxib, a cyclooxygenase-2 inhibitor, in familial adenomatous polyposis. N. Engl. J. Med. 342, 1946-1952.

Sugiyama, A., Maruta, F., Ikeno, T., Ishida, K., Kawasaki, S., Katsuyama, T., Shimizu, N. and Tatematsu, M. (1998) Helicobacter pylori infection N-methyl-N-nitrosourea-induced stomach carcinogenesis in the Mongolian Gerbils. Cancer Res. 58, 2067-2069.

Sung, J. J., Keung, W. K., Go, M. Y. Y., To, K. F., Cheng, A. S. L., Ng, E. K. W. and Chan, F. K. (2000) Cyclooxygenase-2 expression in Helicobacter pylori-associated premalignant and malignant gastric lesions. Am. J. Pathol. 157, 729-735.

Suzuki, M., Miura, S., Mori, M., Kai, A., Suzuki, H., Fukumura, D., Suematsu, M. and Tsuchiya, M. (1994) Rebamipide, a novel antiulcer agent, attenuates Helicobacter pylori induced gastric mucosal cell injury associated with neutrophil derived oxidants. Gut 35, 1375-1378.

Uemura, N., Okamoto, S., Yamamoto, S., Matsumura, N., Yamaguchi, S., Yamakido, M., Taniyama, K., Sasaki, N. and Schlemper, R. J. (2001) Helicobacter pylori infection and the development of gastric cancer. N. Engl. J. Med. 345, 784-789.

Wang, J., Fan, X., Lindholm, C., Bennett, M., OConnoll, J., Shanahan, F., Brooks, E. G., Reyes, V. E. and Ernst, P. B. (2000) Helicobacter pylori modulates lymphoepithelial cell interactions leading to epithelial cell damage through Fas/Fas ligand interactions. Infect. Immun. 68, 4303-4311.

Yamaoka, Y., Kita, M., Kodama, T., Sawai, N. and Imanishi, J. (1996) Helicobacter pylori cagA gene and expression of cytokine messenger RNA in gastric mucosa. Gastroenterology 110, 1744-1752.

Yamaoka, Y., Kodama, T., Kita, M., Imanishi, J., Kashima, K. and Graham, D. Y. (2001) Relation between cytokines and Helicobacter pylori in gastric cancer. Helicobacter 6, 116-124.

Yamasaki, K., Kanbe, T., Chijiwa, T., Ishiyama, H. and Morita, S. (1987) Gastric mucosal protection by OPC-12579, a novel antiulcer compound, in the rats. Eur. J. Pharmacol. 142, 23-30.

Yoshida, N., Granger, D. N., Evans, D. J., Evans, D. G., Graham, D. Y., Anderson, D. C, Wolf, R. E. and Kvietys, P. R. (1993) Mechanisms involved in Helicobacter pylori-induced inflammation. Gastroenterology 105, 1431-1440.

Yoshida, N., Yoshikawa, T., Iinuma, S., Arai, M., Takenaka, S., Sakamoto, K., Miyajima, T., Nakamura, Y., Yagi, N., Naito, Y., Mukai, F. and Kondo, M. (1996) Rebamipide protects against 
activation of neutrophils by Helicobacter pylori. Dig. Dis. Sci. 41, 1139-1144.

Zhang, O. B., Nakashabendi, I.M., Mokhashi, M.S., Dawodu, J. B., Gemmell, C. G. and Russell, R. I. (1996) Association of cytotoxin production and neutrophil activation by strains of Helicobacter pylori isolated from patients with peptic ulceration and chronic gastritis. Gut 38, 841-845. 